of this book, the well-known media scholar, Brian McNair (2006) condemns the authors for their disapproval of 'new girl' columnists (as exemplified by Candace Bushell and 'Bridget Jones'), suggesting that they have swallowed the idea that women's journalism has 'dumbed down' the media as a whole. Yet they themselves state that 'news is not inherently feminine or masculine. It is therefore not helpful to refer to the postmodern shift to infotainment as a "feminisation" of news' ( $p$. 230). It would appear that they are attempting a more complex argument in which market forces are driving news towards the personal and emotional ('soft' news), which has historically been seen by the male editors and owners as the women's realm, thus creating more job opportunities for women, but only if they play up to the stereotype. From their feminist point of view, therefore, the authors consider it as both a positive and a negative development.

Sadie Clifford

\title{
reference
}

McNair, B. (2006) 'Book review: Women and journalism', Media, Culture and Society, Vol. 28, No. 1: 153-154.

doi: $10.1057 /$ palgrave.fr. 9400392

\section{Femme fatalities: representations of strong women in the media}

Rikke Schubart and Anne Gjelsvik, editors; Nordicom, Gothenburg, 2004, 233p,

ISBN 91-89471-25-3, \$25

Femmes Fatalities: Representations of Strong Women in the Media is an anthology of essays addressing and questioning the alleged rise of powerful women in the media fictions of the 1990s. This highly eclectic collection of twelve essays ranges geographically from Scandinavia to South America, and covers the wide range of genres and sites that comprise the contemporary field of media reception and analysis.

Obviously covering all bases (and contributions) is beyond the confines of a single review, but in general the very diversity of Femme Fatalities is part of its strength - but primarily its weakness. This is a very mixed bag divided into three somewhat arbitrary sections (New Media and Postfeminist Aesthetics, Genre Fictions and From the Margins). The collection is marred by a lack of theoretical focus or direction, in the absence of which the editors have latched onto the term 'postfeminism' as a catch-all umbrella term for the project.

As Rikke Schubart and Anne Gjelsvik write in their introduction: 'Taken together, the essays in this anthology are representative for [sic] a postfeminist approach 
to culture in the sense that none of them provide simple answers to complex questions' (p. 10-11).

This apparently rests on the highly problematic assumption that feminist theory, as opposed to postfeminist theory, does not take account of complexity and diversity, also in the field of film and cultural studies. After nine lines galloping from midnineteenth century 'first-wave' feminism to the 1960s (as if there has been no feminism since), the authors claim that 'Postfeminism ... differs from feminism in having a positive approach to patriarchy, popular culture and postmodernism' (p. 12).

With such stereotyping of feminism, and apparent approval of 'patriarchy', one wonders why the word feminism (with or without prefixes) is used at all.

Unfortunately, the text is also marred by a degree of editorial laxness, which in several instances requires an effort on the part of the reader that would be better used on content than form, although this is a minor quibble given the main issue I have with the text: the inclusion of Ilsa, She-Wolf of the SS in this collection of 'strong women'.

Rikke Schubart describes the film as starting with a speech by Hitler ending with repeated Sieg Heils, before we get to the bedroom/torture chamber where she locates the remainder of her analysis. Seeing, in She-Wolf, 'the subversion of binary oppositions' everywhere, Schubart claims the 'unease' at watching the film to be solely generated by its inventory of taboo fantasies and portrayal of male masochism, and ends by positing the Nazi Ilsa as a potential postfeminist heroine: 'How shall we understand the figure of Ilsa: Is she a strong woman representing the subversion of patriarchy and male aggression? Does she turn stereotypical gender roles upside down?' (p. 198)

Rikke Schubart's surprise that the film and its sequels have not previously been included in serious academic studies might just have something to do with the fact that concentration camp imagery and Nazism is somewhere people (quite rightly) choose not to go - and that any claims of female liberation on that account are highly criticizable. Ilsa prancing around in a Nazi uniform sticking bombs triggered by penile penetration in women's vaginas and wielding a goosestepping castration knife seriously calls into question the academic integrity of analysing any woman in this particular political, historical and iconographic context as potentially 'empowering'.

These serious issues do not, however, apply to all the essays included in the anthology, many of which provide solid, well-researched contributions to contemporary debates using a wide range of media texts, female figures and theoretical approaches.

Ingrid Lindell offers a more empirical approach, identifying the 'exception' she argues strong women continue to be in the media landscape. Of the 2,000 films broadcast and screened in Sweden during 1996 a meagre 3 per cent were by and 
about women. Lindell interestingly identifies parallels between mainstream and 'alternative' films, where one might expect to find more differentiated representations than in the mainstream. Looking at these films and the dominance of rape and prostitution within them, as well as the critical practices surrounding them (e.g., reviews of Lars von Trier's Breaking the Waves) Lindell reveals the prevalent censorship of gender analysis in reviewing practice.

Gender ambiguities and contradictions play a central role in the analyses of Lara Croft and Buffy the Vampire Slayer included in the anthology. Just as, according to Maja Mikula, Lara Croft can be criticized for having Barbie-doll proportions, she can also be seen to embody physical strength and power. Similarly Buffy, in Deneka C. MacDonald's excellent analysis, is 'iconic eye candy', yet has both brawn and brain - although in the final analysis she apparently has to have 'both power and sex appeal to be successful'.

This is apparently less true of the heroines of Norwegian thrillers analysed by Anne Gjelsvik. With their realistic representation of modern working women, Gjelsvik presents the sexualization of Hollywood female heroines as being significantly downplayed in films that are closer to women's real lives, a realism that also characterizes the role of female doctors in the TV series $\varepsilon R$. In her analysis of the series, Marvi Pantti links the erasure of gender binaries to its 'genre cocktail' and multilayered characters. She identifies these developments as being partly motivated by the commercial desire to reach 'cross-over' audiences and the targeting of women by advertisers (a scepticism of commercialism shared by other contributors), but still argues that the presence of strong women on television can play a crucial role in changing minds and possibly politics by destabilizing gender boundaries.

Such destablization is equally interestingly analysed in the figure of Lola in Run Lola Run (Kim Walden), women as American soldiers (Yvonne Tasker) and Xena: Warrior Princess (Walter Alesci). One can only hope that these authors are comfortable sheltering under the postfeminist umbrella the editors have raised over the anthology.

doi: 10.1057/palgrave.fr. 9400394

Jane Rowley

\section{Impossible desires: queer diasporas and South Asian public cultures}

Gayatri Gopinath; Duke University Press, Durham and London, 2005, 264p, ISBN 0-8223-3513-1, £14.95 (Pbk); ISBN-13 978-0822335139, £60 (Hbk)

As part of the growing literature on the South Asian diaspora, Impossible Desires attempts to offer a new perspective, which addresses both shortcomings in 